\title{
Unplanned reoperation after lumbopelvic fixation with S-2 alar-iliac screws or iliac bolts
}

\author{
Marcus D. Mazur, MD, ${ }^{1}$ Vijay M. Ravindra, MD, ${ }^{1}$ Meic H. Schmidt, MD, MBA, ${ }^{1}$ Darrel S. Brodke, MD, ${ }^{2}$ \\ Brandon D. Lawrence, MD, ${ }^{2}$ Jay Riva-Cambrin, MD, MSc, ${ }^{1}$ and Andrew T. Dailey, MD1
}

Departments of ${ }^{1}$ Neurosurgery and ${ }^{2}$ Orthopaedics, Clinical Neurosciences Center, University of Utah, Salt Lake City, Utah

\begin{abstract}
OBJECT S-2 alar-iliac (S2AI) screws are an attractive alternative to conventional fixation with iliac bolts because they are lower profile, require less muscle dissection, and have greater pullout strength. Few studies, however, compare outcomes between these techniques.

METHODS The authors conducted a retrospective cohort study of consecutive adult patients at a single institution from December 2009 to March 2012 who underwent lumbopelvic fixation using S2AI screws or iliac bolts. Medical records were reviewed for patients with clinical failure, defined as an unplanned reoperation because of instrumentation failure and/or wound-related complications. Univariate, multivariate, and survival analyses were used to compare patients who required reoperation with those who did not. Method of pelvic fixation was the main predictor variable of interest, and the authors adjusted for potential confounding risk factors.
\end{abstract}

RESULTS Of the 60 patients included, 23 received S2AI screws. Seventeen patients (28\%) underwent an osteotomy. The mean follow-up was 22 months. A Kaplan-Meier survival model was used to evaluate the time to reoperation from the initial placement of lumbopelvic instrumentation. The failure-free rate was $96.6 \%$ at 6 months, $87.0 \%$ at 1 year, and $73.5 \%$ at 2 years. Reoperation was more common in patients with iliac bolts than in those with S2AI screws (13 vs 2; $p=0.031$ ). Univariate analysis identified potential risk factors for unplanned reoperation, including use of iliac bolts $(p=0.031)$, absence of L5-S1 interbody graft ( $p=0.048)$, previous lumbar fusion $(p=0.034)$, and pathology other than degenerative disease or scoliosis $(p=0.034)$. After adjusting for other risk factors, multivariate analysis revealed that the use of S2Al screws (OR 8.1 [1.5-73.5]; $p=0.030$ ) was the only independent predictor for preventing unplanned reoperation.

CONCLUSIONS Both S2AI screws and iliac bolts were effective at improving fusion rates at the lumbosacral junction. The use of S2Al screws, however, was independently associated with fewer unplanned reoperations for wound-related complications and instrumentation failures than the use of iliac bolts.

http://thejns.org/doi/abs/10.3171/2014.10.SPINE14541

KEY WORDS pelvic fixation; S-2 alar-iliac screws; iliac bolts; reoperation; sacral

$\mathrm{U}$ NPLANNED reoperation after surgery for adult lumbar spine deformity is costly, in terms of both direct costs and health care resource utilization. It was recently estimated that revision fusion surgery in the lumbar spine has an estimated average cost of $\$ 28,000 .{ }^{1}$ Frequent causes of reoperation in this patient population include wound infection/breakdown, implant failure, pseudarthrosis, and removal of instrumentation because of pain..$^{21,25,29,30}$ From a patient's standpoint, the high rates of complications and reoperation associated with lumbar deformity surgery are an important factor to be considered in the initial decision to proceed with surgery.
There has been an increase in the use of lumbopelvic fixation to potentially decrease complications and improve results. It is often used to correct pelvic obliquity, reduce strain on S-1 pedicle screws, provide rigid immobilization for L5-S1, repair pseudarthrosis, reduce highgrade spondylolisthesis, or bolster the caudal end of a construct spanning a lumbosacral defect due to infection or tumors. The recently developed method of pelvic fixation using S-2 alar-iliac (S2AI) screws has several potential advantages over traditional iliac bolts, namely greater cortical purchase and lower profile. S2AI screws can also be aligned with rostral instrumentation without the use of

ABBREVIATIONS BMP = bone morphogenetic protein; ODI = Oswestry Disability Index; S2AI = S-2 alar-iliac screw .

SUBMITTED June 2, 2014. ACCEPTED October 23, 2014.

INCLUDE WHEN CITING Published online April 3, 2015; DOI: 10.3171/2014.10.SPINE14541.

DISCLOSURE Dr. Brodke reports that he is a consultant for Amedica and DePuy Synthes and has direct stock ownership in Amedica. He reports receiving royalty payments from Amedica, DePuy, and Medtronic. Dr. Dailey reports that he is a consultant for Biomet and an education consultant for AONA. 
bulky offset connector devices. ${ }^{23,28}$ The purpose of this study was to investigate whether the use of S2AI screws is associated with lower rates of unplanned reoperation in patients undergoing pelvic fixation compared with those receiving iliac bolts. Knowledge of the risk factors and timing of unplanned reoperation will enable surgeons to counsel patients more effectively during preoperative discussions.

\section{Methods \\ Data Collection}

The study was approved by the institutional review board prior to data collection. A search of the operative database for the period of December 2009 to March 2012 identified all operations in which pelvic fixation with either iliac bolts or S2AI screws were used. All patients undergoing pelvic fixation during this time period were included in the study cohort, including those undergoing pelvic fixation as the initial operation and those requiring pelvic fixation for a revision operation. To ensure the study groups were consecutive and concurrent, procedures performed prior to December 2009 were excluded. Follow-up data were recorded until the end of November 2013.

The medical records and postoperative images of patients who underwent lumbopelvic fixation were reviewed. Clinical variables and surgical details were recorded, including sex, age, date of surgery, Oswestry Disability Index (ODI) score at baseline and at the most recent clinic visit, number of previous lumbar fusion operations, method of pelvic fixation, S2AI screws or iliac bolts, reason for lumbopelvic fixation, number of levels fused, placement of an L5-S1 interbody graft, use of bone morphogenetic protein (BMP), and whether an osteotomy was performed. The reason for lumbopelvic fixation was categorized as 1) primary surgery for scoliosis or degenerative disease; 2) revision surgery for failed lumbar fusion, symptomatic pseudarthrosis, or iatrogenic flat-back syndrome; or 3) primary surgery for osteolytic pathology, such as an infection or tumor (i.e., chordoma).

\section{Surgical Technique}

A standard midline posterior incision was made, and the instrumentation was inserted using an open technique. Iliac bolts were inserted in a standard fashion with fluoroscopic guidance. Stereotactic image guidance (O-arm Surgical Imaging System/StealthStation, Medtronic, Inc.) was used for placement of S2AI screws, using a previously described technique..$^{28}$

The extent of soft-tissue dissection differed between the methods of pelvic fixation. For placement of iliac bolts, subperiosteal dissection was performed to the posterior superior iliac spines. A high-speed drill was used to make a starting point $1 \mathrm{~cm}$ rostral to the inferior end of the posterior superior iliac spine and $1 \mathrm{~cm}$ deep to its superficial ridge. A blunt probe was inserted and angled toward the sciatic notch. The hole length was measured, the hole was tapped, and the iliac bolt was inserted under fluoroscopic guidance using the $\mathrm{C}$-arm with tear drop and lateral views. Bolts that are 7.5-9.0 $\mathrm{mm}$ in diameter and $80-100 \mathrm{~mm}$ in length are typically used. In this location, the polyaxial pelvic screw heads are buried deep to the superficial ridge of the posterior superior iliac spine to decrease hardware prominence at the most bony structure that individuals feel when they sit against a chair. ${ }^{35}$ Connector devices are used to link the iliac bolts to rostral instrumentation (Fig. 1A).

For placement of S2AI screws, the extent of muscle and fascia dissection is less than that required for iliac bolts because of a more medial starting point of the screw. Subperiosteal dissection on the sacrum was limited to the exposure of entry points located $5 \mathrm{~mm}$ caudal and 2-3 $\mathrm{mm}$ lateral to the S-1 foramen. A high-speed bur drill is used to mark the starting point. Using the O-arm Surgical Imaging System, the screw trajectory is angled toward the greater trochanter, rostral to the sciatic notch. This trajectory enables the screw to cross the cortical surfaces of the sacroiliac joint and engage the dense bone above the sciatic notch. A custom blunt probe traverses the planned trajectory using real-time image guidance. The hole is measured and tapped, and the S2AI screw is inserted. We commonly use S2AI screws that are $8.0-8.5 \mathrm{~mm}$ in diameter and $80-100 \mathrm{~mm}$ in length. The head of the S2AI screw is aligned with rostral instrumentation without the need for connector devices (Fig. 1B).

\section{Outcomes}

The primary outcome of clinical failure was defined as an unplanned reoperation during the study period for instrumentation failure or wound-related complications. Reasons for reoperation included loosening or breakage of instrumentation, symptomatic pseudarthrosis, wound breakdown at the caudal end of the incision over the pelvic instrumentation, or removal of pelvic fixation because of
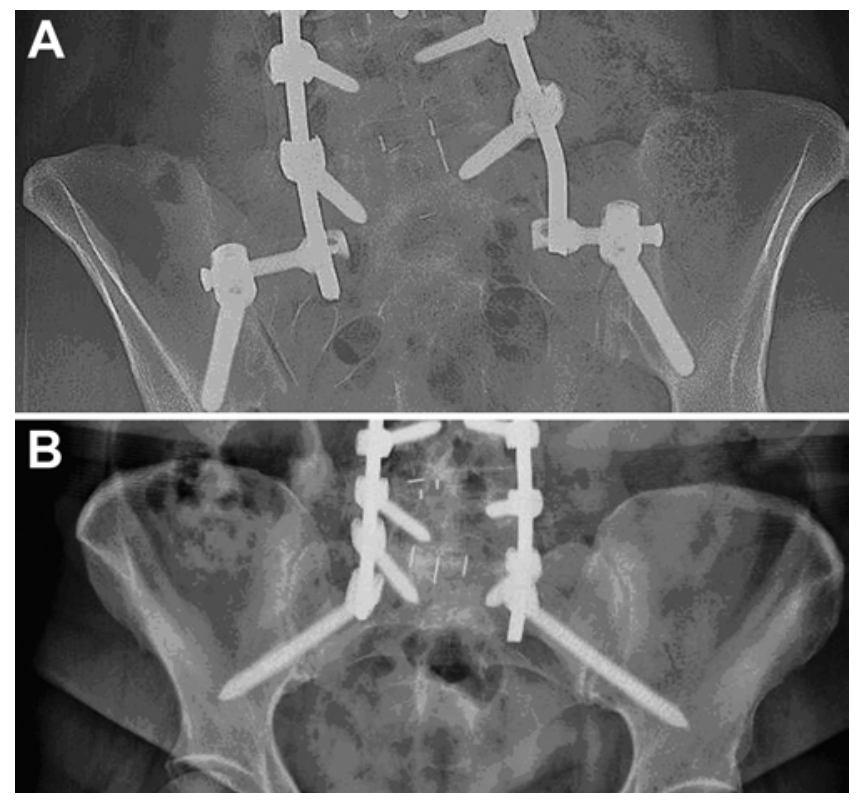

FIG. 1. A: Radiograph depicting iliac bolts with offset connector devices used for linking pelvic fixation to rostral instrumentation. B: Radiograph depicting S2Al screws, which are aligned with rostral instrumentation so that the use of offset connector devices is not needed. 
pain due to hardware prominence. We excluded revision operations performed for proximal junctional kyphosis because we considered this a sequela and part of the natural history of long-segment fusions and not a failure of the initial operation. The second portion of a staged procedure, such as posterior lumbopelvic instrumentation and fusion followed by an anterior lumbar interbody fusion, was not considered as a reoperation.

\section{Predictor Variables}

The main predictor variable of interest was method of pelvic fixation: S2AI screws or iliac bolts. In addition, we evaluated potential confounding risk factors for unplanned reoperation. Patient factors included demographics, history of previous lumbar spine operations, and reason for lumbopelvic fixation. Surgical factors included number of levels fused, whether an osteotomy was performed, use of BMP, and placement of an L5-S1 interbody graft.

\section{Statistical Analysis}

Cohort characteristics at baseline and surgical details were summarized overall and by outcome depending on whether a revision operation was performed. Fisher's exact tests and Student t-tests were used for univariate analyses on categorical and continuous variables, respectively, to identify potential predictors of unplanned reoperation, including the predictor variable of interest, i.e., method of pelvic fixation. Variables that reached significance or near significance on univariate analysis were then included in a multivariate analysis using a stepwise logistic regression model to test for the association between method of pelvic fixation and unplanned reoperation while controlling for possible confounders. Colinearity was tested between continuous variables using Pearson correlation coefficients. Categorical variables included in the model were assessed for interdependence using Fisher's exact tests. Kaplan-Meier survival analysis was performed, with patients stratified according to method of pelvic fixation, using time to reoperation for causal outcome and time to follow-up otherwise. A probability value $<0.05$ was considered statistically significant and $<0.10$ was considered near-significant. As a test of sensitivity, a log-rank test was also conducted with time to unplanned reoperation as the outcome. Statistical analysis was performed using R software (version 3.0.2, R Foundation for Statistical Computing, http://www.R-project.org).

\section{Results}

\section{Patient Characteristics and Surgical Details}

Our study population included 60 patients who underwent pelvic fixation: 37 received iliac bolts and 23 received S2AI screws (Table 1). Nineteen patients were male $(32 \%)$. The mean patient age $( \pm \mathrm{SD})$ was $62 \pm 13$ years (range 26-78 years). The median baseline ODI was 48 (interquartile range 40-61). Thirty-five patients underwent pelvic fixation as a primary surgery for degenerative disease or scoliosis (58\%); 20 as a revision operation, failed lumbar fusion, or flat-back syndrome (33\%); and 5 as a primary operation for an osteolytic pathology (8\%) involving infection (4 patients) or tumor (1 patient, chordoma).
TABLE 1. Baseline characteristics and surgical details of patients who underwent lumbopelvic fixation*

\begin{tabular}{|c|c|c|c|}
\hline Variable & All Patients & $\begin{array}{l}\text { Patients } \\
\text { w/ S2Al } \\
\text { Screws }\end{array}$ & $\begin{array}{l}\text { Patients w/ } \\
\text { Iliac Bolts }\end{array}$ \\
\hline No. of patients & 60 & 23 & 37 \\
\hline No. of males & $19(32)$ & $10(43)$ & $9(24)$ \\
\hline Mean age in years & $62 \pm 13$ & $58 \pm 14$ & $64 \pm 11$ \\
\hline Smoking history & 7 (12) & $3(13)$ & $4(11)$ \\
\hline \multicolumn{4}{|l|}{ Baseline ODI } \\
\hline Median & 48 & 54 & 44 \\
\hline IQR & $40-61$ & $46-54$ & $40-56$ \\
\hline \multicolumn{4}{|l|}{$\begin{array}{l}\text { Reason for lumbopelvic } \\
\text { fixation }\end{array}$} \\
\hline $\begin{array}{l}\text { Scoliosis or degenerative } \\
\text { disease }\end{array}$ & $35(58)$ & $11(48)$ & $24(65)$ \\
\hline Failed lumbar fusion & $20(33)$ & $8(35)$ & $12(32)$ \\
\hline Infection or tumor & $5(8)$ & $4(17)$ & $1(3)$ \\
\hline $\begin{array}{l}\text { Previous lumbar fusion } \\
\text { surgery }\end{array}$ & $25(42)$ & $11(48)$ & $14(38)$ \\
\hline Mean no. of levels fused & $8.1 \pm 4.1$ & $6.8 \pm 3.6$ & $8.8 \pm 4.2$ \\
\hline Osteotomy & $17(28)$ & $3(13)$ & $14(38)$ \\
\hline BMP & $46(77)$ & $12(52)$ & $34(92)$ \\
\hline \multicolumn{4}{|l|}{ L5-S1 interbody graft } \\
\hline Anterior approach & $11(18)$ & $7(30)$ & $4(11)$ \\
\hline Posterior approach & $28(47)$ & $9(39)$ & $19(51)$ \\
\hline Previous graft present & $3(5)$ & $2(9)$ & $1(3)$ \\
\hline No graft & $18(30)$ & $5(22)$ & $13(35)$ \\
\hline
\end{tabular}

The mean number of levels fused was $8.1 \pm 4$.1. Seventeen patients (28\%) underwent an osteotomy.

\section{Primary Analysis \\ Outcomes}

The mean follow-up was 22 months (median 23 months, range $2-41$ months). Fifteen patients $(25 \%)$ required an unplanned reoperation, the primary outcome of interest. Indications for reoperation included instrumentation failure or nonunion between L-1 and L-5 (9 cases), failure or nonunion at L5-S1 (2 cases), removal of pelvic fixation hardware because of its painful prominence ( 3 cases), wound breakdown over pelvic fixation requiring debridement and wound revision ( 2 cases), and pelvic screw backout (1 case) (Table 2).

For patients undergoing an unplanned reoperation, the mean ODI score was $49.7 \pm 18.8$ preoperatively and improved to $44.4 \pm 18.0$ postoperatively. For those not undergoing reoperation, the mean ODI score was $48.9 \pm$ 13.5 preoperatively and improved to $36.6 \pm 22.4$ postoperatively. The difference in ODI for patients undergoing reoperation compared with those who did not was not statistically significant at either the preoperative or most 
TABLE 2. Cases requiring reoperation after pelvic fixation

\begin{tabular}{|c|c|c|c|c|c|}
\hline $\begin{array}{l}\text { Case } \\
\text { No. }\end{array}$ & $\begin{array}{l}\text { Age (yrs), } \\
\text { Sex }\end{array}$ & Reason for Pelvic Fixation & Procedure & $\begin{array}{l}\text { Time to Reop } \\
\text { (mos) }\end{array}$ & Reason for Reop \\
\hline 1 & $64, \mathrm{M}$ & $\begin{array}{l}\text { Revision surgery/flat-back } \\
\text { syndrome }\end{array}$ & T10-ilium PSF, iliac bolts, BMP & 2 & $\begin{array}{l}\text { Progressive deformity; backout of iliac } \\
\text { bolts; backout of L-4, L-5, \& S-1 } \\
\text { screws }\end{array}$ \\
\hline 2 & $39, F$ & $\begin{array}{l}\text { Revision surgery/flat-back } \\
\text { syndrome }\end{array}$ & $\begin{array}{l}\text { T3-ilium PSF, iliac bolts, ALIF } \\
\text { L5-S1, BMP }\end{array}$ & 1 & Wound breakdown over pelvic fixation \\
\hline 3 & $42, \mathrm{~F}$ & $\begin{array}{l}\text { Revision surgery/L5-S1 } \\
\text { nonunion }\end{array}$ & $\begin{array}{l}\text { L2-ilium PSF, iliac bolts, ALIF } \\
\text { L5-S1 }\end{array}$ & 30 & L5-S1 rod fracture, increased back pain \\
\hline 4 & $68, F$ & Primary surgery, scoliosis & T10-ilium PSF, iliac bolts, BMP & 14 & Iliac bolts removed because of pain \\
\hline 5 & $66, F$ & Revision surgery, scoliosis & T10-ilium PSF, iliac bolts, BMP & 8 & $\begin{array}{l}\text { L3-4 nonunion w/ rod fracture, in- } \\
\text { creased back pain }\end{array}$ \\
\hline 6 & $50, F$ & Primary surgery, scoliosis & $\begin{array}{l}\text { T3-ilium PSF, iliac bolts, L5-S1 } \\
\text { TLIF, BMP }\end{array}$ & 23 & $\begin{array}{l}\text { L3-4 nonunion w/ rod fracture, in- } \\
\text { creased back pain }\end{array}$ \\
\hline 7 & $61, F$ & Primary surgery, scoliosis & $\begin{array}{l}\text { T1-ilium PSF, iliac bolts, L-3 } \\
\text { osteotomy, BMP }\end{array}$ & 12 & Iliac bolts removed because of pain \\
\hline 8 & $75, \mathrm{M}$ & Primary surgery, osteomyelitis & L2-ilium PSF, iliac bolts & 12 & Iliac bolts removed because of pain \\
\hline 9 & $35, \mathrm{M}$ & Primary surgery, chordoma & $\begin{array}{l}\text { T10-ilium PSF, S2AI screws, } \\
\text { L1-3 vertebrectomy }\end{array}$ & 18 & $\begin{array}{l}\text { L3-4 rod fracture, wound dehiscence } \\
\text { over iliac bolts }\end{array}$ \\
\hline 10 & $76, M$ & $\begin{array}{l}\text { Revision surgery, L5-S1 } \\
\text { nonunion }\end{array}$ & $\begin{array}{l}\text { L1-ilium PSF, iliac bolts, L5-S1 } \\
\text { TLIF, BMP }\end{array}$ & 5 & L1-2 nonunion, myelopathy \\
\hline 11 & $65, M$ & $\begin{array}{l}\text { Revision surgery, L5-S1 non- } \\
\text { union, flat-back syndrome }\end{array}$ & $\begin{array}{l}\text { T4-ilium PSF, iliac bolts, L-3 } \\
\text { osteotomy, BMP }\end{array}$ & 25 & L2-3, L3-4 nonunion, increased pain \\
\hline 12 & $47, M$ & $\begin{array}{l}\text { Revision surgery, L5-S1 non- } \\
\text { union, flat-back syndrome }\end{array}$ & $\begin{array}{l}\text { L1-ilium PSF, iliac bolts, L-4 } \\
\text { osteotomy, L5-S1 TLIF, BMP }\end{array}$ & 17 & L1-2 nonunion, increased pain \\
\hline 13 & $69, \mathrm{~F}$ & $\begin{array}{l}\text { Revision surgery, failed lumbar } \\
\text { fusion }\end{array}$ & $\begin{array}{l}\text { T10-ilium PSF, iliac bolts, L-3 } \\
\text { osteotomy, BMP }\end{array}$ & 19 & L3-4 nonunion, increased pain \\
\hline 14 & $67, \mathrm{~F}$ & $\begin{array}{l}\text { Revision surgery, sagittal } \\
\text { imbalance }\end{array}$ & $\begin{array}{l}\text { T3-ilium PSF, S2Al screws, T-12 } \\
\text { osteotomy, BMP }\end{array}$ & 10 & L1-2 rod fracture, increased pain \\
\hline 15 & $70, F$ & $\begin{array}{l}\text { Revision surgery, flat-back } \\
\text { deformity }\end{array}$ & $\begin{array}{l}\text { T2-ilium PSF, iliac bolts, L1-4 } \\
\text { osteotomy, BMP }\end{array}$ & 7 & L3-4 rod fracture, increased pain \\
\hline
\end{tabular}

ALIF = anterior lumbar interbody fusion; PSF = posterior spinal fusion; TLIF = transforaminal lumbar interbody fusion.

recent postoperative clinic visit $(p=0.90$ and $p=0.28$, respectively).

\section{Risk Factors for Unplanned Reoperation}

Several potential risk factors for an unplanned reoperation were identified on univariate analysis (Table 3), including use of iliac bolts $(p=0.031)$, reason for lumbopelvic fixation other than primary surgery for degenerative disease or scoliosis $(\mathrm{p}=0.034)$, previous lumbar fusion $(\mathrm{p}=0.034)$, not receiving an L5-S1 interbody graft $(\mathrm{p}=$ $0.048)$, number of levels fused ( $\mathrm{p}=0.068)$, and undergoing an osteotomy $(\mathrm{p}=0.099)$. These factors were included in a multivariate regression model. After adjusting for the other risk factors, the use of S2AI screws was the only independent predictor for preventing an unplanned reoperation $(\mathrm{p}=0.030$; OR 8.1 [95\% CI 1.5-73.5]) (Table 3).

\section{Secondary Analysis}

Survivor Analysis for Time to Reoperation

A Kaplan-Meier survival model was used to evaluate the time to reoperation from the initial placement of lumbopelvic instrumentation. Reoperations for instrumenta- tion revision, instrumentation removal, or wound revision were considered to be failures. For all patients included in this study, the failure-free rate was $96.6 \%$ at 6 months, $87.0 \%$ at 12 months, $79.6 \%$ at 18 months, and $73.5 \%$ at 24 months. Survival analysis comparing the time to failure for patients receiving iliac bolts with that for patients receiving S2AI screws suggested a trend toward fewer failures over time with the use of S2AI screws (log-rank, $\mathrm{p}=$ 0.10) (Fig. 2).

\section{Examining Failure at the Lumbosacral Junction}

For complications at the lumbosacral junction, there was a trend toward fewer unplanned reoperations in patients with S2AI screws than those with iliac bolts (1 vs 6 , respectively; $p=0.23$ ), although our sample size was too small to demonstrate statistical significance. In this subgroup, only 1 patient with S2AI screws underwent reoperation. This patient had undergone T10-ilium posterior fusion after a multilevel vertebrectomy for an invasive chordoma. After receiving $6000 \mathrm{cGy}$ of fractionated radiation therapy, he required reoperation for wound breakdown over the pelvic fixation. Of the 6 patients with iliac 
TABLE 3. Univariate analyses and multivariate logistic regression analysis of variables associated with reoperation after lumbopelvic fixation*

\begin{tabular}{|c|c|c|c|c|c|}
\hline \multirow[b]{2}{*}{ Variable } & \multirow[b]{2}{*}{ Reop } & \multirow[b]{2}{*}{ No Reop } & \multirow{2}{*}{$\begin{array}{c}\text { Univariate } † \\
\text { p Value }\end{array}$} & \multicolumn{2}{|c|}{ Multivariate $\dagger$} \\
\hline & & & & $p$ Value & OR $(95 \% \mathrm{Cl})$ \\
\hline No. of patients & 15 & 45 & - & & \\
\hline No. of males & $6(40)$ & $13(29)$ & 0.52 & & \\
\hline Mean age in yrs & $60 \pm 13$ & $62 \pm 12$ & 0.62 & & \\
\hline Smoking history & $2(13)$ & $5(11)$ & 1.00 & & \\
\hline Baseline ODI & & & 0.89 & & \\
\hline Median & 43 & 50 & & & \\
\hline IQR & $39-63$ & $40-60$ & & & \\
\hline Lumbopelvic fixation & & & 0.031 & 0.030 & $8.1(1.5-73.5)$ \\
\hline S2Al screws & $2(13)$ & $21(47)$ & & & \\
\hline Iliac bolts & $13(87)$ & $24(53)$ & & & \\
\hline \multicolumn{6}{|l|}{ Reason for lumbopelvic fixation } \\
\hline Scoliosis or degenerative disease & $5(33)$ & $30(67)$ & 0.034 & 0.10 & $0.1(0.01-1.3)$ \\
\hline Failed lumbar fusion/flat back & $8(53)$ & $12(27)$ & 0.11 & & \\
\hline Infection or tumor & $2(13)$ & $3(7)$ & 0.59 & & \\
\hline Previous lumbar fusion surgery & $10(67)$ & $15(33)$ & 0.034 & 0.65 & $1.7(0.2-16.7)$ \\
\hline Mean no. of previous fusions & $2.2 \pm 1.1$ & $1.5 \pm 0.9$ & 0.055 & & \\
\hline Mean no. of levels fused & $10.0 \pm 4.8$ & $7.4 \pm 3.6$ & 0.068 & 0.19 & $1.1(0.9-1.4)$ \\
\hline Osteotomy & $7(47)$ & $10(22)$ & 0.099 & 0.62 & $1.5(0.3-8.8)$ \\
\hline BMP & $12(80)$ & $34(76)$ & 1.00 & & \\
\hline L5-S1 interbody graft & $7(47)$ & $35(78)$ & 0.048 & 0.13 & $0.3(0.1-1.4)$ \\
\hline
\end{tabular}

bolts who had complications at the lumbosacral junction, 2 had instrumentation failure, 3 required removal of pelvic fixation because of pain, and 1 had wound breakdown over the iliac bolts. Patients who did not receive an L5-S1 interbody graft were more likely to undergo an unplanned reoperation for any complication at the lumbosacral junction $(\mathrm{p}=0.021)$. None of the other potential risk factors were statistically significant on univariate analysis (data not shown).

\section{Examining Failure Above the Lumbosacral Junction}

Eight patients underwent an unplanned reoperation for instrumentation failure above the lumbosacral junction (Table 4). After univariate analysis, the number of levels fused $(p=0.063)$, the use of osteotomy $(p=0.005)$, and the absence of an L5-S1 interbody graft $(p=0.045)$ were identified as potential risk factors for unplanned reoperation. These variables were included in a multivariate regression analysis, but none of these were independent predictors for unplanned reoperation for failure above the lumbosacral junction (Table 4). Moreover, the difference in reoperation rates for complications above the lumbosacral junction among patients with S2AI screws and iliac bolts was not statistically significant $(13 \%$ and $27 \%$, respectively; $\mathrm{p}=0.33$ ).

\section{Fractured Instrumentation Not Requiring Reoperation}

Five patients with iliac bolts experienced fractured in- strumentation but did not undergo reoperation. One patient had a fractured iliac bolt, 2 had rod fractures at the lumbosacral junction, and 2 had rod fractures above the lumbosacral junction. Reoperation was not performed because patients either had a successful arthrodesis or were asymptomatic. No patient had fractured S2AI screws.

\section{Discussion}

S2AI screws have potential advantages over traditional iliac bolts, namely greater cortical purchase, lower profile, and ease of alignment with rostral instrumentation without the use of offset connector devices. S2AI screws can be placed under conventional fluoroscopic imaging or by using image-guided stereotactic navigation. In 2009, we began to insert S2AI screws in some patients during lumbopelvic fixation in response to failure of traditional iliac fixation. Complications we had observed in patients who received iliac bolts included painful implant prominence, muscle and fascial closures under tension with subsequent need for revision, symptomatic pseudarthrosis, and iliac bolt loosening or breakage prior to lumbosacral arthrodesis. In this retrospective review, we investigated concurrent cohorts of consecutive patients undergoing pelvic fixation to determine whether the use of S2AI screws was protective against complications requiring reoperation. This is the first study to compare unplanned reoperation rates in patients undergoing insertion of S2AI screws versus those receiving iliac bolts. 


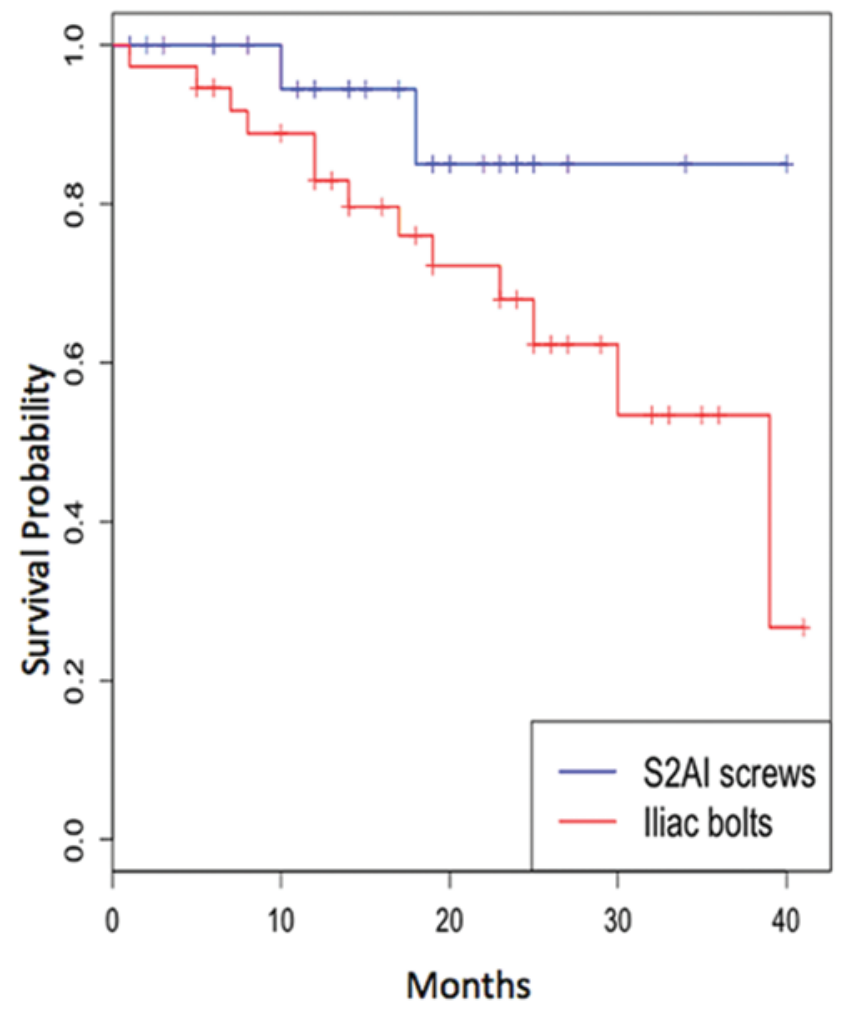

FIG. 2. Kaplan-Meier survival probabilities demonstrating a trend toward fewer reoperations in patients receiving S2AI screws than in those receiving iliac bolts (log-rank, $p=0.10$ ). Figure is available in color online only.

\section{Risk Factors for Unplanned Reoperation}

After controlling for potential confounders, we found that the use of S2AI screws was the only factor protective against unplanned reoperation in patients undergoing pelvic fixation. Patients with S2AI screws underwent fewer unplanned reoperations for symptomatic instrumentation failure, wound breakdown, and removal of pelvic fixation because of painful prominence than those who received iliac bolts. Factors that did not have an independent association with unplanned reoperation included the number of levels fused, the presence of an osteotomy, reason for pelvic fixation, prior lumbar fusion, and the placement of an L5-S1 interbody graft.

\section{Failure-Free Rate}

The reoperation rate for adult spinal deformity varies from $6 \%$ to $60 \%, 7,10,14,21,25,30$ with an increased trend toward reoperation in patients 60 years or older., ${ }^{9,12} \mathrm{We}$ report an unplanned reoperation rate of $25 \%$ in patients undergoing pelvic fixation $(8.6 \%$ for S2AI screws vs $35 \%$ for iliac bolts). Considering reoperation as a failure in a Kaplan-Meier survival model, we found a failure-free rate of $96.6 \%$ at 6 months, $87.0 \%$ at 12 months, $79.6 \%$ at 18 months, and $73.5 \%$ at 24 months, overall for all patients. This is consistent with findings reported in other studies. ${ }^{21,30}$ Most instances of unplanned reoperation in our study, aside from proximal junctional failure, occurred between 6 and 18 months after the initial surgery. After including the component of time in the analysis, the difference in failure between S2AI screws and iliac bolts demonstrated a trend toward a decrease in failure rate with S2AI screws, but the difference was no longer statistically significant (log-rank test, $\mathrm{p}=0.11$ ), which may be in part because of the small sample size and the shorter duration of follow-up. Mid- and long-range follow-up of these cohorts may divulge further discrepancy between these techniques due to increasing prominence of painful hardware related to the iliac bolts or issues related to immobilization of the sacroiliac joint with the S2AI screws.

\section{Pseudarthrosis}

Symptomatic pseudarthrosis with instrumentation failure was the most frequent reason for unplanned reoperation in our cohort, occurring in $66 \%$ of patients. Of the 10 cases with symptomatic pseudarthrosis, 8 occurred between L-1 and L-5. Only 2 patients in this study underwent reoperation for symptomatic L5-S1 pseudarthrosis (Cases 1 and 3). This is consistent with results of other studies that have reported a similar trend with modern instrumentation techniques, ${ }^{10}$ the use of pelvic fixation to bolster the caudal end of the construct, ${ }^{34}$ and the use of BMP. ${ }^{4}$ Pedicle screw fixation at the lower instrumented vertebra is more rigid than constructs anchored in the lumbar spine with hooks and wires. ${ }^{5}$ Pelvic fixation further increases the construct's biomechanical rigidity at the lumbosacral junction. .11,19,20,33 $^{2}$ In patients undergoing lumbopelvic fixation, L5-S1 pseudarthrosis may manifest by rod breakage at this level. ${ }^{34}$

Many surgeons consider that the role of pelvic fixation is to protect the S-1 screws. A recent review, however, included failure at the level above the lumbosacral junction (L4-5) as a major complication of pelvic fixation. ${ }^{8}$ This phenomenon may occur because of construct failure originating at either the rostral or caudal end. Possible mechanisms of both types of failure are described below.

The use of offset connectors with iliac bolts provides an additional point where loosening of the construct may occur that is not present with S2AI screws, which obviates the use of offset connectors since S2AI screws are aligned with rostral instrumentation. This would decrease the strength of the lumbopelvic fixation construct and may cause loosening of the S-1 screws and, subsequently, pedicle screws at the adjacent segments. In addition, traditional iliac fixation does not cross cortical bone and may loosen overtime. Tsuchiya et al. ${ }^{34}$ reported iliac bolt lucency in 29 of 67 patients with a minimum 5-year follow-up. Although the initial pullout strength of S2AI screws is superior to that of iliac bolts, ${ }^{36}$ both types of fixation protect the S-1 screw from strain to an equivalent degree. ${ }^{16}$ Over time, however, the superior purchase of the S2AI screws may confer long-term protection to the lumbosacral and lumbar fusion beds.

In addition, lumbopelvic fixation constructs may be more rigid at the caudal end, which creates a moment arm that may cause either backout of the rostral instrumentation or fracture of the rods. In this scenario, rostral instrumentation failure may represent the natural history of a long-segment construct with rigid lumbopelvic fixation. This mechanism would explain failure that occurs 2 or more levels above the lumbosacral junction. To prevent 
TABLE 4. Subanalysis of variables associated with reoperation for a complication above the lumbosacral junction*

\begin{tabular}{|c|c|c|c|c|c|}
\hline \multirow[b]{2}{*}{ Variable } & \multirow[b]{2}{*}{ Reop } & \multirow[b]{2}{*}{ No Reop } & \multirow{2}{*}{$\begin{array}{c}\text { Univariate } † \\
\text { p Value }\end{array}$} & \multicolumn{2}{|c|}{ Multivariate } \\
\hline & & & & $p$ Value & $\mathrm{OR}(95 \% \mathrm{Cl})$ \\
\hline No. of patients & 13 & 47 & & & \\
\hline No. of males & $5(38)$ & $8(30)$ & 0.73 & & \\
\hline Mean age in years & $63 \pm 12$ & $61 \pm 13$ & 0.61 & & \\
\hline Smoking history & $2(15)$ & $5(11)$ & 0.64 & & \\
\hline Baseline ODI & & & 0.58 & & \\
\hline Median & 42 & 50 & & & \\
\hline IQR & $18-78$ & $26-80$ & & & \\
\hline Lumbopelvic fixation & & & 0.33 & & \\
\hline S2Al screws & $3(23)$ & $20(43)$ & & & \\
\hline Iliac bolts & $10(77)$ & $27(57)$ & & & \\
\hline \multicolumn{6}{|l|}{ Reason for lumbopelvic fixation } \\
\hline Scoliosis or degenerative disease & $6(46)$ & $29(62)$ & 0.35 & & \\
\hline Failed lumbar fusion/flat back & $5(38)$ & $15(42)$ & 0.74 & & \\
\hline Infection or tumor & $2(15)$ & $3(6)$ & 0.29 & & \\
\hline Previous lumbar fusion surgery & $6(46)$ & $19(40)$ & 0.76 & & \\
\hline Mean no. of previous fusions & $1.7 \pm 1.1$ & $1.7 \pm 0.9$ & 0.97 & & \\
\hline Mean no. of levels fused & $10.3 \pm 4.8$ & $7.4 \pm 3.6$ & 0.063 & 0.19 & $1.1(0.9-1.3)$ \\
\hline Osteotomy & $8(61)$ & $9(19)$ & 0.005 & 0.62 & $3.6(0.8-17.3)$ \\
\hline BMP & $11(85)$ & $35(74)$ & 0.71 & & \\
\hline L5-S1 interbody graft & $6(46)$ & $36(77)$ & 0.045 & 0.13 & $0.4(0.1-1.7)$ \\
\hline
\end{tabular}

rod fracture and pseudarthrosis above the lumbosacral junction, we have adopted the use of the 4-rod technique after an osteotomy is performed (Fig. 3), although none of the patients included received 4 rods at the time of pelvic fixation. Four-rod constructs are biomechanically stiffer in flexion-extension loading than conventional dual-rod constructs, and the added cross-links further increase the stiffness in torsion. ${ }^{18}$

Regardless of the underlying cause of rostral instrumentation failure in patients undergoing lumbopelvic fixation, we observed significantly fewer unplanned reoperations in patients receiving S2AI screws than in those receiving iliac bolts. While it is possible that the association between unplanned reoperation and method of pelvic fixation is due to chance alone, the multivariate models that we used for analysis were robust. After controlling for several potential confounders, the use of S2AI screws was identified as an independent predictor against unplanned reoperation in multiple regression models that included stepwise techniques, such as forward selection, backward elimination, and bidirectional elimination, as well as hand-selected models. These statistical results suggest that an association exists between unplanned reoperation and method of pelvic fixation, even if the underlying biomechanical explanation has not yet been elucidated.

\section{Painful Hardware Prominence}

Pain associated with implant prominence is a frequent reason for reoperation in patients who receive instru- mented fusions for adult spinal deformities, ${ }^{5,10}$ particularly in patients with iliac bolts who require offset connectors to link to rostral instrumentation. ${ }^{32,34}$ In 67 patients who underwent pelvic fixation with iliac bolts, over one-third underwent elective removal of their iliac bolts because of painful prominence. ${ }^{34}$ This type of pain commonly occurs in a delayed fashion several months to years after the initial operation..$^{10}$ In our study, pelvic implant removal for pain occurred after 12-14 months. Patients reported improvement at the site of painful prominence, although postoperative ODI scores remained stable after hardware removal. Although many surgeons try to recess the head of the iliac bolt deep to the superficial surface of the posterior superior iliac spine, hardware prominence is a frequent complaint, particularly in young and thin patients. ${ }^{34}$ Three of the 37 patients $(8 \%)$ in our study who received iliac bolts underwent removal of the pelvic fixation because of painful hardware prominence, which is consistent with the rates of iliac bolt removal reported in other studies (3\%34\%). ${ }^{8,15,17,24,34}$ The rate of patients experiencing pain relief after implant removal varies widely $(12 \%-70 \%) ., 2,3,10,13,31$ Removal of instrumentation is not a benign procedure, and previous studies have reported progression of deformity after removal. ${ }^{4,13,22,26,27}$

The heads of S2AI screws, in contrast, are positioned deeper and more medial than those of iliac bolts and have more extensive soft-tissue coverage. The starting point for an S2AI screw is located approximately $5 \mathrm{~mm}$ caudal and 2-3 mm lateral to the first sacral foramen, ${ }^{28}$ which is ap- 


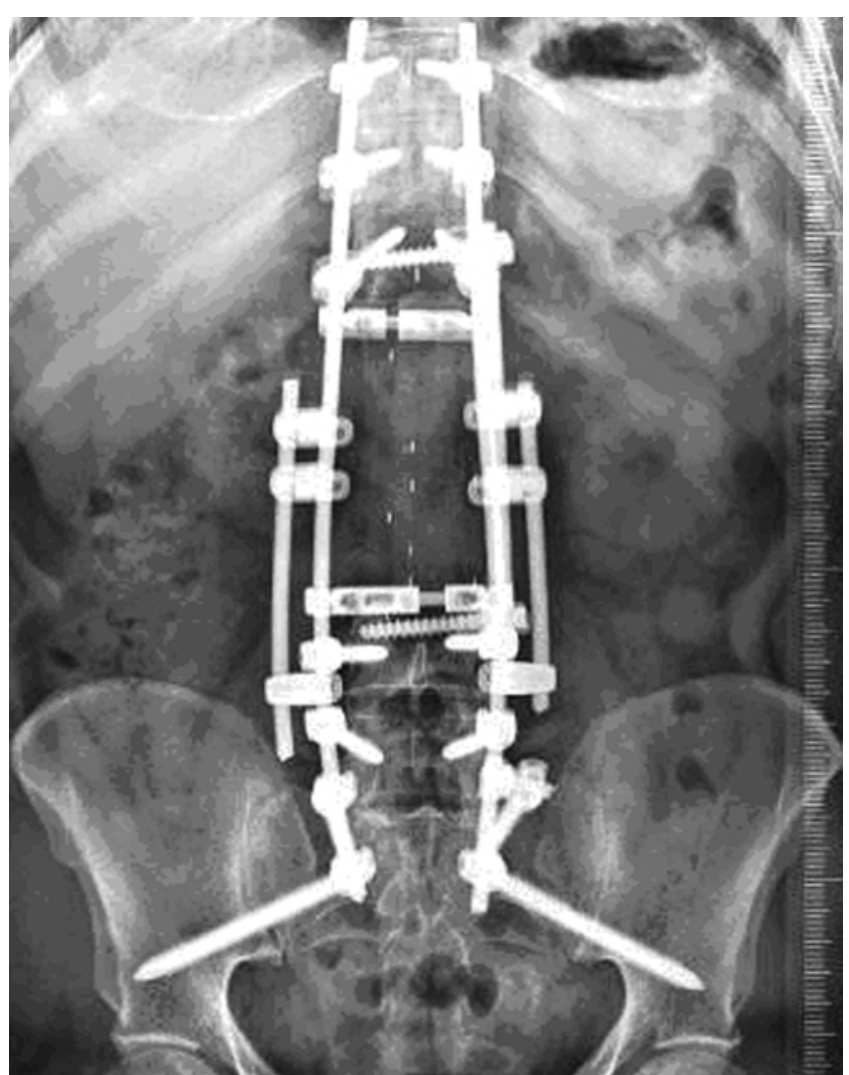

FIG. 3. Radiograph demonstrating placement of 4 rods with cross-links in a patient who underwent a 3-level vertebral body resection for chordoma invading $\mathrm{L} 1-3$ and required reoperation for a rod fracture at the level of the vertebral column resection.

proximately $15 \mathrm{~mm}$ deeper than the entry point of an iliac bolt on the posterior superior iliac spine. ${ }^{6}$ This enables S2AI screws to be lower profile with more muscle and fascial coverage. Because the starting point is more medial on the sacrum, less dissection of paraspinal muscles and the subcutaneous tissues over the iliac spine is required. In addition, the S2AI screw head can be aligned with the S-1 pedicle screw and rostral instrumentation without the use of bulky connector devices, given that the starting point is directly inferior to the superior articular facet of S-1 and in line with the pedicles of the lumbar spine. ${ }^{6}$ None of the 23 patients in our cohort who received S2AI screws required removal of the pelvic fixation for pain or screw fracture.

\section{Limitations}

Limitations of the study include the retrospective design and a relatively short follow-up period. The reasons for lumbopelvic fixation varied between the 2 groups. S2AI screw fixation was used more frequently during revision surgery for failed lumbar fusion, symptomatic pseudarthrosis, or iatrogenic flat-back syndrome and also primary surgery for osteolytic pathology, such as infection and tumor. Iliac bolt fixation was used more frequently as primary surgery for adult scoliosis or degenerative disease. The decision to proceed with reoperation was up to the treating surgeon, which may introduce selection bias. For example, some surgeons may be more aggressive at revising rod fractures in asymptomatic patients, whereas others based their reoperation criteria on the status of the arthrodesis on CT scanning and patient symptomatology. Postoperative imaging protocols also varied in that some surgeons favored the use of routine CT scans at 1- to 2-year follow-up to evaluate the arthrodesis in all patients, whereas others obtained CT scans only if there was suspicion for symptomatic pseudarthrosis. The majority of patients who required reoperation did not undergo CT scanning prior to the revision surgery, so the integrity of pedicle and pelvic screw purchase or the arthrodesis could not be determined reliably. In addition, all S2AI screws were placed using image-guidance stereotaxy, but iliac bolts were placed under fluoroscopic guidance. The use of stereotaxy may enable more accurate screw placement than fluoroscopy, although, to our knowledge, this has not been examined for pelvic fixation. Lastly, our study was not adequately powered or designed to evaluate differences in clinical improvement as assessed using the ODI. The small sample size, heterogeneous group of patients, and short follow-up are potential reasons a significant difference or a minimal clinical important difference was not seen.

\section{Future Considerations}

In this study, we demonstrated that both S2AI screws and iliac bolts prevent failure at L5-S1 in a patient population that is at high risk for developing L5-S1 pseudarthrosis. Given the low rate of complications at the lumbosacral junction, we postulate that similar outcomes can be achieved with iliac bolts that are positioned more inferiorly on the iliac spine so that the bolt head can be aligned with the S-1 pedicle screw without a connector device. In this scenario, the difference between the S2AI screw and a "low-profile" iliac bolt would be the screw trajectory: an S2AI screw would cross the iliac crest and achieve tricortical bone fixation, but an iliac bolt would be positioned in cancellous bone between the cortical tables of the iliac crest; both screw tips are anchored in the dense bone above the sciatic notch. Either method of pelvic fixation may be adequate for bolstering the caudal end of an instrumented construct, considering a recent biomechanical study that found that the additional cortical purchase with S2AI screws did not improve their biomechanical strength in a nonfatigue model. ${ }^{23}$ By obviating the need for offset connectors, this method of "low-profile" iliac bolt placement should also decrease the risk of wound breakdown and hardware prominence.

This retrospective study provides preliminary evidence that the S2AI screw technique may result in fewer revision surgeries than traditional techniques for iliac fixation. To validate any improvement in patient outcome or decrease in revision rates, a prospective study will need to be completed.

\section{Avoiding Reoperation}

Unplanned reoperation represents an additional procedure in patients who may already be at a significant risk for complication. From a patient's standpoint, the risk of reoperation may be an important factor in the initial decision to proceed with surgery. Knowledge of the rate, reason, and time of reoperation will better enable the surgeon 
to counsel patients during preoperative discussions and may increase awareness of problems that commonly occur postoperatively. From a health care standpoint, reoperations for potentially preventable causes are extremely cost ineffective. New surgical techniques and devices that can decrease unplanned returns to the operating room are valuable.

\section{Conclusions}

Both S2AI screws and iliac bolts are effective at improving fusion rates at the lumbosacral junction. Based on a multivariate analysis, we found that the use of S2AI screws was independently associated with fewer reoperations for wound-related complications and instrumentation failures. The low profile of S2AI screws and the benefit of obviating the use of offset connectors may offer additional advantages when compared with traditional iliac bolts.

\section{References}

1. Adogwa O, Owens R, Karikari I, Agarwal V, Gottfried ON, Bagley CA, et al: Revision lumbar surgery in elderly patients with symptomatic pseudarthrosis, adjacent-segment disease, or same-level recurrent stenosis. Part 2. A cost-effectiveness analysis. Clinical article. J Neurosurg Spine 18:147-153, 2013

2. Alanay A, Vyas R, Shamie AN, Sciocia T, Randolph G, Wang JC: Safety and efficacy of implant removal for patients with recurrent back pain after a failed degenerative lumbar spine surgery. J Spinal Disord Tech 20:271-277, 2007

3. Alpert HW, Farley FA, Caird MS, Hensinger RN, Li Y, Vanderhave KL: Outcomes following removal of instrumentation after posterior spinal fusion. J Pediatr Orthop 34:613-617, 2014

4. Annis P, Spiker WR, Lawarence BD, Daubs MD, Brodke DS: Paper 5. The fate of L5-S1 with low dose BMP-2 and pelvic fixation in adult deformity surgery. Abstracts of the 2014 Annual Meeting of the Lumbar Spine Research Society, Chicago, Illinois, May 1-2, 2014. Neurosurg Focus 36(4):A3, 2014 (Abstract)

5. Asher MA, Lai SM, Burton DC: Analysis of instrumentation/fusion survivorship without reoperation after primary posterior multiple anchor instrumentation and arthrodesis for idiopathic scoliosis. Spine J 10:5-15, 2010

6. Chang TL, Sponseller PD, Kebaish KM, Fishman EK: Low profile pelvic fixation: anatomic parameters for sacral alariliac fixation versus traditional iliac fixation. Spine (Phila Pa 1976) 34:436-440, 2009

7. Charosky S, Guigui P, Blamoutier A, Roussouly P, Chopin D: Complications and risk factors of primary adult scoliosis surgery: a multicenter study of 306 patients. Spine (Phila Pa 1976) 37:693-700, 2012

8. Cho W, Mason JR, Smith JS, Shimer AL, Wilson AS, Shaffrey CI, et al: Failure of lumbopelvic fixation after long construct fusions in patients with adult spinal deformity: clinical and radiographic risk factors. Clinical article. J Neurosurg Spine 19:445-453, 2013

9. Cloyd JM, Acosta FL Jr, Cloyd C, Ames CP: Effects of age on perioperative complications of extensive multilevel thoracolumbar spinal fusion surgery. J Neurosurg Spine 12:402408, 2010

10. Cook S, Asher M, Lai SM, Shobe J: Reoperation after primary posterior instrumentation and fusion for idiopathic scoliosis. Toward defining late operative site pain of unknown cause. Spine (Phila Pa 1976) 25:463-468, 2000

11. Cunningham BW, Lewis SJ, Long J, Dmitriev AE, Linville DA, Bridwell KH: Biomechanical evaluation of lumbosacral reconstruction techniques for spondylolisthesis: an in vitro porcine model. Spine (Phila Pa 1976) 27:2321-2327, 2002

12. Daubs MD, Lenke LG, Cheh G, Stobbs G, Bridwell KH: Adult spinal deformity surgery: complications and outcomes in patients over age 60. Spine (Phila Pa 1976) 32:22382244, 2007

13. Deckey JE, Court C, Bradford DS: Loss of sagittal plane correction after removal of spinal implants. Spine (Phila Pa 1976) 25:2453-2460, 2000

14. Edwards CC II, Bridwell KH, Patel A, Rinella AS, Berra A, Lenke LG: Long adult deformity fusions to L5 and the sacrum. A matched cohort analysis. Spine (Phila Pa 1976) 29:1996-2005, 2004

15. Emami A, Deviren V, Berven S, Smith JA, Hu SS, Bradford DS: Outcome and complications of long fusions to the sacrum in adult spine deformity: luque-galveston, combined iliac and sacral screws, and sacral fixation. Spine (Phila Pa 1976) 27:776-786, 2002

16. Kang DG, Lehman RA Jr, Tracey RW, Gaume RE, Cody JP, Kebaish KM, et al: Paper 22. Sacral screw strain in a long posterior spinal fusion construct with sacral alar-iliac (S2AI) versus iliac fixation. Abstracts of the 2014 Annual Meeting of the Lumbar Spine Research Society, Chicago, Illinois, May 1-2, 2014. Neurosurg Focus 36(4):A11-A12, 2014 (Abstract)

17. Kasten MD, Rao LA, Priest B: Long-term results of iliac wing fixation below extensive fusions in ambulatory adult patients with spinal disorders. J Spinal Disord Tech 23:e37e42, 2010

18. Kelly BP, Shen FH, Schwab JS, Arlet V, Diangelo DJ: Biomechanical testing of a novel four-rod technique for lumbo-pelvic reconstruction. Spine (Phila Pa 1976) 33:E400-E406, 2008

19. Lebwohl NH, Cunningham BW, Dmitriev A, Shimamoto N, Gooch L, Devlin V, et al: Biomechanical comparison of lumbosacral fixation techniques in a calf spine model. Spine (Phila Pa 1976) 27:2312-2320, 2002

20. McCord DH, Cunningham BW, Shono Y, Myers JJ, McAfee PC: Biomechanical analysis of lumbosacral fixation. Spine (Phila Pa 1976) 17 (8 Suppl):S235-S243, 1992

21. Mok JM, Cloyd JM, Bradford DS, Hu SS, Deviren V, Smith JA, et al: Reoperation after primary fusion for adult spinal deformity: rate, reason, and timing. Spine (Phila Pa 1976) 34:832-839, 2009

22. Muschik M, Lück W, Schlenzka D: Implant removal for late-developing infection after instrumented posterior spinal fusion for scoliosis: reinstrumentation reduces loss of correction. A retrospective analysis of 45 cases. Eur Spine J 13:645-651, 2004

23. O’Brien JR, Yu W, Kaufman BE, Bucklen B, Salloum K, Khalil S, et al: Biomechanical evaluation of S2 alar-iliac screws: effect of length and quad-cortical purchase as compared with iliac fixation. Spine (Phila Pa 1976) 38:E1250E1255, 2013

24. O'Shaughnessy BA, Lenke LG, Bridwell KH, Cho W, Zebala LP, Chang MS, et al: Should symptomatic iliac screws be electively removed in adult spinal deformity patients fused to the sacrum? Spine (Phila Pa 1976) 37:1175-1181, 2012

25. Pichelmann MA, Lenke LG, Bridwell KH, Good CR, O'Leary PT, Sides BA: Revision rates following primary adult spinal deformity surgery: six hundred forty-three consecutive patients followed-up to twenty-two years postoperative. Spine (Phila Pa 1976) 35:219-226, 2010

26. Potter BK, Kirk KL, Shah SA, Kuklo TR: Loss of coronal correction following instrumentation removal in adolescent idiopathic scoliosis. Spine (Phila Pa 1976) 31:67-72, 2006

27. Rathjen K, Wood M, McClung A, Vest Z: Clinical and radiographic results after implant removal in idiopathic scoliosis. Spine (Phila Pa 1976) 32:2184-2188, 2007

28. Ray WZ, Ravindra VM, Schmidt MH, Dailey AT: Stereotactic navigation with the $\mathrm{O}$-arm for placement of $\mathrm{S}-2$ alar 
iliac screws in pelvic lumbar fixation. J Neurosurg Spine 18:490-495, 2013

29. Richards BS, Hasley BP, Casey VF: Repeat surgical interventions following "definitive" instrumentation and fusion for idiopathic scoliosis. Spine (Phila Pa 1976) 31:3018-3026, 2006

30. Sánchez-Mariscal F, Gomez-Rice A, Izquierdo E, Pizones J, Zúñiga L, Álvarez-González P: Survivorship analysis after primary fusion for adult scoliosis. Prognostic factors for reoperation. Spine J 14:1629-1634, 2014

31. Stavridis SI, Bücking P, Schaeren S, Jeanneret B, Schnake KJ: Implant removal after posterior stabilization of the thoraco-lumbar spine. Arch Orthop Trauma Surg 130:119-123, 2010

32. Stevens DB, Beard C: Segmental spinal instrumentation for neuromuscular spinal deformity. Clin Orthop Relat Res (242):164-168, 1989

33. Tis JE, Helgeson M, Lehman RA, Dmitriev AE: A biomechanical comparison of different types of lumbopelvic fixation. Spine (Phila Pa 1976) 34:E866-E872, 2009

34. Tsuchiya K, Bridwell KH, Kuklo TR, Lenke LG, Baldus C: Minimum 5-year analysis of L5-S1 fusion using sacropelvic fixation (bilateral S1 and iliac screws) for spinal deformity. Spine (Phila Pa 1976) 31:303-308, 2006

35. Tumialán LM, Mummaneni PV: Long-segment spinal fixation using pelvic screws. Neurosurgery 63 (3 Suppl):183-190, 2008

36. Wong C, Corn C, Crosby C, Even J, Mencio GA, Devin CJ, et al: 225. Biomechanical analysis of iliac screws versus S2 alar-iliac screws. Abstracts of the 2011 Meeting of the AANS/CNS Section on Disorders of the Spine and Peripheral Nerves, March 2011. Neurosurg Focus 30(3):A15, 2011 (Abstract)

\section{Author Contributions}

Conception and design: Dailey, Mazur. Acquisition of data: Mazur, Ravindra. Analysis and interpretation of data: Dailey, Mazur, Riva-Cambrin. Drafting the article: Mazur. Critically revising the article: all authors. Reviewed submitted version of manuscript: Dailey, Mazur, Ravindra, Brodke, Lawrence, RivaCambrin. Approved the final version of the manuscript on behalf of all authors: Dailey. Study supervision: Dailey.

\section{Correspondence}

Andrew T. Dailey, Department of Neurosurgery, University of Utah, 175 N. Medical Dr. E, Salt Lake City, UT 84132. email: andrew.dailey@hsc.utah.edu. 